\title{
Exhaled Jet and Viral-Laden Aerosol Transport from Nasal Sneezing
}

\section{Aerosol and Air Quality Research}

Special Issue:

Special Issue on Air Quality in a Changed World: Regional, Ambient, and Indoor Air Concentrations from the COVID to Post-COVID Era (IV)

\section{OPEN ACCESS}

Received: January 3, 2022

Revised: February 24, 2022

Accepted: February 26, 2022

\section{${ }^{*}$ Corresponding Author:}

kiao.inthavong@rmit.edu.au

\section{Publisher:}

Taiwan Association for Aerosol Research

ISSN: $1680-8584$ print

ISSN: 2071-1409 online

(c) Copyright: The Author(s). This is an open access article distributed under the terms of the Creative Commons Attribution License (CC BY 4.0), which permits unrestricted use, distribution, and reproduction in any medium, provided the original author and source are cited.

\author{
Hana Salati ${ }^{1}$, David F. Fletcher ${ }^{2}$, Mehrdad Khamooshi ${ }^{1,3}$, Jingliang Dong ${ }^{1}$, \\ Kazuhide Ito ${ }^{4}$, Sara Vahaji ${ }^{1}$, Kiao Inthavong ${ }^{1 *}$ \\ ${ }^{1}$ School of Engineering, RMIT University, Melbourne 3000, Australia \\ ${ }^{2}$ School of Chemical and Biomolecular Engineering, The University of Sydney, NSW 2006, \\ Australia \\ ${ }^{3}$ Department of Mechanical \& Aerospace Engineering, Monash University, Victoria 3800, \\ Australia \\ ${ }^{4}$ Faculty of Engineering Sciences, Kyushu University, Fukuoka 819-0395, Japan
}

\section{ABSTRACT}

The recognition that the spread of COVID-19 is primarily through airborne transmission has brought renewed urgency to understand the spread of aerosols generated from patients. Viral-laden aerosols generated from oral coughs have been well studied; however, aerosols generated from nasal sneezing has been overlooked. This scenario arises from patients who suffer allergenic rhinosinusitis, or the nasal cavity is irritated, particularly during naso-endoscopy. Nasal sneezing is characterised by an explosive blast of air exiting the nostrils, which can be considered as dual jets, resulting in the spread of viral-laden aerosols remaining suspended in the air. This study used computational fluid dynamics consisting of a hybrid RANS-LES turbulence method to model the airflow and the discrete phase model to track aerosol dispersion during nasal sneezing. The results demonstrated that the exhaled airflow jets during nasal sneezing resemble the flow characteristics of two parallel jets in co-flow. These two jets interfere with each other in the merging zone, and after they merge, the sneeze plume expands radially. The nasal sneeze forms a V-shaped plume with smaller particles in the core region. At the end of the sneeze, when the exhaled jets have lost their initial momentum, the large particle dispersion is dominated by gravity. We detected the presence of a 'sneeze puff that transport droplets away from the body, similar to the buoyant puff observed in recent COVID-19 studies of oral coughs.

Keywords: Aerosol dispersion, CFD, Sneeze jet, Nasal cavity, Droplet evaporation

\section{INTRODUCTION}

It is widely accepted that the spread of COVID-19 is highly transmissible by airborne transmission, arising through the inhalation of viral-laden aerosols exhaled through coughing or sneezing from an infected person (Arumuru et al., 2020; Diwan et al., 2020). Aerosols exhaled through coughing, sneezing, talking, and breathing by an infected person introduces an inhalation exposure risk to nearby people for respiratory infection. Direct close contact of large particles produced by coughing or sneezing is approximately one meter (Leder and Newman, 2005; Morawska, 2005), while aerosols introduced by sneezing and coughing can travel for 7-8 meters (Bourouiba, 2020).

Aerosols from an infected person can be generated from oral coughs (Johnson et al., 2011), singing (Bahl et al., 2021), and exhalation (Philip et al., 2021). However, medical procedures can also generate aerosols, known as aerosol-generating procedures (e.g., tracheal intubation, tracheotomy, cardiopulmonary resuscitation). An overlooked scenario is aerosol generation from nasal sneezing despite how common allergenic rhinosinusitis is among the general population. Furthermore, when the nasal cavity is irritated, such as during naso-endoscopy, or inflamed, the nose experiences a tickly, itchy sensation leading to sneezing. 
During nasal sneezing, the soft palate closes, and the tongue elevates to guide the ejected air from the lungs through the nose (Mygind and Dahl, 1998). High momentum jets are discharged from both nostrils and simultaneously interact with each other and the ambient air. However, up to now, numerical studies have primarily focused on characterising aerosol-cloud formation from coughs, sneeze, and talking produced from the oral cavity (Johnson et al., 2011; Lee et al., 2019; Wang et al., 2020; Stadnytskyi et al., 2021; El Hassan et al., 2022), as well as aerosol dispersion inside a room (Inthavong et al., 2013; Heschl et al., 2014; Ji et al., 2018; Tao et al., 2020; Bathula et al., 2021; Crawford et al., 2021; Shah et al., 2021; Shrestha et al., 2021) and outdoor environments (Feng et al., 2020; Gorbunov, 2021). Additionally, studies (Zhu et al., 2006; Scharfman et al., 2016) demonstrated the oral cough produced a droplet-laden cough jet and puff dynamics, as well as review articles on the fluid dynamics of respiratory droplets (Dbouk and Drikakis, 2020; Mittal et al., 2020; Katre et al., 2021), and mitigation strategies for reducing viral transmission (Hui et al., 2012; Khosronejad et al., 2020; Salati et al., 2021).

Ge et al. (2021) modelled a cough jet for $10 \mathrm{~s}$ of physical time and showed that higher room temperatures caused a shorter cough jet and droplet penetration. Behera et al. (2021) showed that the cough jet temporal evolution is similar to that of a continuous free jet and that the jet travelled approximately $1.1 \mathrm{~m}$ in half a second. With co-flow, the jet travelled faster and further. Fabregat et al. (2021) showed a cough jet in two parts, the initial jet stage and a dissipative phase over which turbulence intensity decayed.

Previous studies have investigated the influence of indoor ventilation on aerosol distribution. The flow path between the contaminant source and the exhaust vent is crucial for controlling the airborne aerosol. The contagion is better managed when the exhaust is closer to the patient source (Thatiparti et al., 2017). Cao et al. (2015) characterised the interaction between a downward jet plane and virus-laden particles within a room. The results demonstrated that utilizing downward jet with high velocities reduces inter-personal exposure to coughed particles. Feng et al. (2021) performed a parametric analysis to investigate how a portable ultraviolet's operating conditions impacted the filtration efficiency in a patient room. The filtration efficiency was defined as reducing the concentration of suspended virus-laden droplets escaping from the room into the central ventilation system. They concluded that the air cleaner's higher ventilation flow rate provided the highest filtration efficiency.

These previous studies mainly focused on the aerosol expelled from the mouth, and nasal sneezing has not been considered. An irritant often triggers nasal sneezing to the nose, whether a pollutant or invasive medical treatments (e.g., nasoendoscopic inspection). The established findings (Feng et al., 2020; Fontes et al., 2020) of oral cough jets demonstrated that expelled droplets maintain their initial momentum with the airflow jet direction. However, two co-flowing jets are moving together for nasal sneezing, which is expected to demonstrate different airflow and aerosol dispersion than oral sneezing and coughing.

There is a relation between the droplet size and viral loading based according to Poisson distribution (Anand and Mayya, 2020). A virus has a discrete nature, and viral incorporation into the droplets expelled from humans depends on the statistical fluctuations (Duguid, 1946). An experimental study revealed that the viral loading is higher in larger particles (Alonso et al., 2015). The same finding (Zuo et al., 2013) stated that the virus-laden droplet size distribution transition towards larger particles following a power law with an exponent greater than three.

Due to the rapid transmission of the COVID-19 worldwide, the spread of the injected aerosol from sneezing or coughing is a critical concern (Zhang et al., 2020). While previous studies have investigated oral coughs, few have examined the airflow dynamics of the human exhalation flows during nasal breathing. Salati et al. (2021) investigated the airflow dynamics of nasal respiration with and without an $\mathrm{N} 95$ respirator at $30 \mathrm{~L} \mathrm{~min}^{-1}$ respiration rate. The results demonstrated that the exhaled airflow jets from the nostrils move downwards and impinge on the respirator's internal surface. Wei et al. (2016) estimated the fraction of the exhaled airflow re-inhaled during the respiration cycle in a pediatric airway replica. They concluded that a very small fraction of the exhaled air volume is re-inhaled in the following breathing cycle. Gupta et al. (2010) investigated the nasal airflow jets during respiration. They characterised the nasal breathing exhaled jets by two front angles and two side angles. These three studies so far (Gupta et al., 2010; Wei et al., 2016; Salati et al., 2021) examined the exhaled airflow jets during regular breathing cycles, which lasts more than $1.65 \mathrm{~s}$. However, during nasal sneezing, the blast of exhaled air through the nostrils 
lasts for approximately $0.4 \mathrm{~s}$, producing different flow characteristics and aerosol dispersion. During nasal sneezing, the droplet injection is located at the nostril, and the airflow coming out from the nostrils is directed towards the ground. Therefore, the airborne viral transmission between people will be different during nasal sneezing. To better understand the transport dynamics of the virus laden aerosols through the air during nasal sneezing, this study applied a hybrid RANS-LES turbulence model to investigate the fluid and particle characteristics of the nasal airflow jets during a 0.4 s sneeze and how they interact with each other.

\section{METHOD}

\subsection{Computational Geometry Model}

The geometry of a seated manikin was used for this study (shown in Fig. 1). A human nasal cavity, extracted from CT scans used in previous studies (Zhang et al., 2019; Inthavong et al., 2020), was included to produce natural exhalation conditions. The nasal airway included the nasopharynx, the paranasal sinuses, and the main nasal passage and the surrounding domain was a room with a floor size of $2 \mathrm{~m} \times 2.2 \mathrm{~m}$ and a height of $2.4 \mathrm{~m}$. The right and left nostril

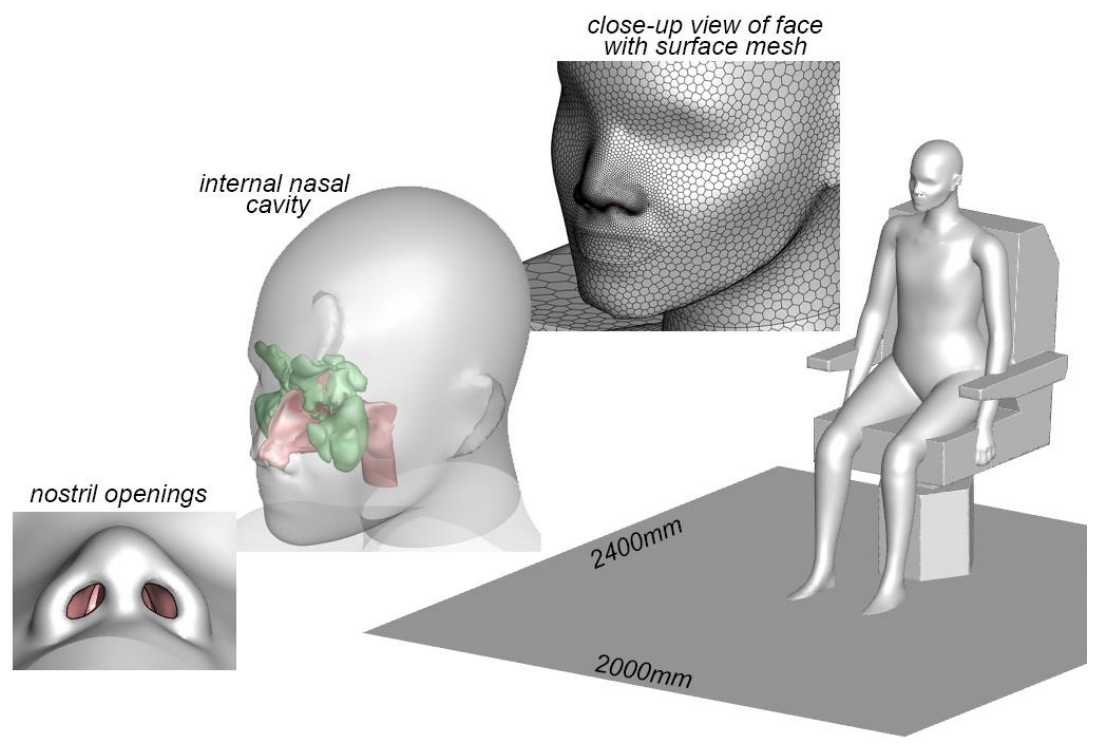

(a) Seated manikin geometry

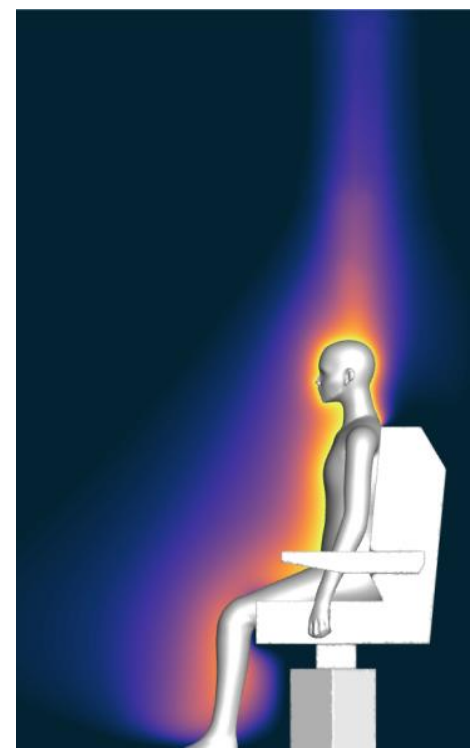

(b) Preliminary steady state

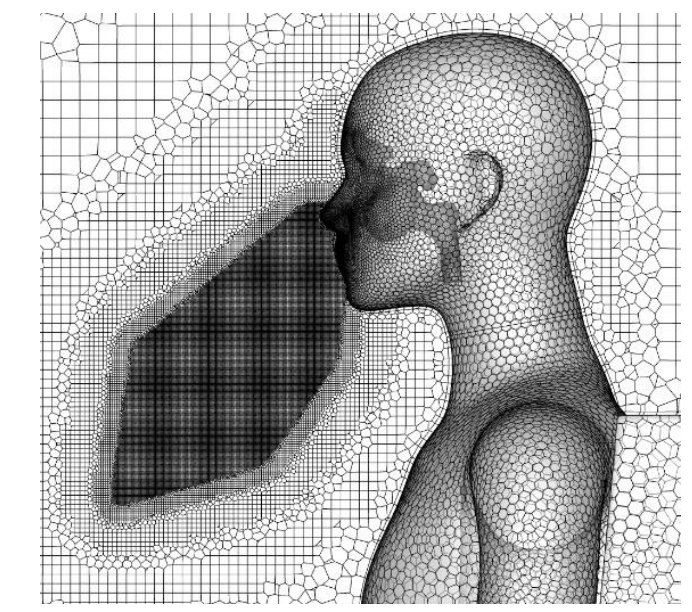

(c) Optimised exhaled sneeze mesh

g. 1. (a) Geometry of a seated manikin with an internal nasal cavity that generates the exhaled airflow, (b) Preliminary steady state flow to establish the human thermal plume, (c) Optimised mesh with highly refined region in the sneeze region, and (d) Zoomed view of the internal nasal cavity that generates the exhaled sneeze. 
openings had a cross-sectional area of $41.1 \mathrm{~mm}^{2}$ and $40.0 \mathrm{~mm}^{2}$, respectively. The model was meshed with poly-hex-core cells and prism layers on the nasal cavity walls using Ansys-Fluent 2019R3. A preliminary mesh was created to establish the exhalation and sneeze plume, and then it was refined (using a body-of-influence) in this region. The highly optimised final mesh contained 3.97 million cells with a concentration of cells in the exhalation plume region (Fig. 1(c)).

\subsection{Airflow Modelling}

A steady simulation was initially performed to establish a natural convection thermal plume flow (Fig. 1(c)). The model was then switched to a transient simulation, and the scale-resolving $k$ - $\omega$ SST-SBES (Stress Blended Eddy Simulation) model was used (Van Strien et al., 2021). This applies the $k-\omega$ SST model in the near-wall region and a Large Eddy Simulation model away from the wall with the switch between the two accomplished using a blending function. Here the WALE subgrid-scale model was used. Large eddies are resolved directly in the LES region, while small eddies are modelled. The subgrid-scale (SGS) stresses resulting from the filtering operation are unknown and require modelling. The subgrid-scale turbulence models in ANSYS Fluent employ the Boussinesq hypothesis (Hinze, 1975) as in the RANS models, computing subgrid-scale turbulent stresses from:

$\tau_{i j}-\frac{1}{3} \tau_{k k} \delta_{i j}=-2 \mu_{t} \bar{S}_{i j}$

where $\mu_{t}$ is the subgrid-scale turbulent viscosity. The isotropic part of the subgrid-scale stresses $\tau_{\mathrm{kk}}$ is not modelled directly but added to the filtered static pressure term. $\bar{S}_{i j}$ is the rate of strain tensor for the resolved scale defined by

$\bar{S}_{i j}=\frac{1}{2}\left(\frac{\partial \bar{u}_{i}}{\partial x_{j}}+\frac{\partial \bar{u}_{j}}{\partial x_{i}}\right)$

In this case, the WALE subgrid-scale model was used, in which the eddy viscosity is modelled by:

$\mu_{t}=\rho L_{s}^{2} \frac{\left(S_{i j}^{d} S_{i j}^{d}\right)^{\frac{2}{3}}}{\left(\bar{S}_{i j}^{d} \bar{S}_{i j}^{d}\right)^{\frac{5}{2}}+\left(S_{i j}^{d} S_{i j}^{d}\right)^{\frac{5}{4}}}$

where $L_{s}$ and $S_{i j}^{d}$ in the WALE model are defined, respectively, as:

$L_{s}=\min \left(\kappa d, C_{\omega} V^{\frac{1}{3}}\right)$

$S_{i j}^{d}=\frac{1}{2}\left(\bar{g}_{i j}^{2}+\bar{g}_{j i}^{2}\right)-\frac{1}{3} \delta_{i j} \bar{g}_{k k}^{2}$

where

$\bar{g}_{i j}=\frac{\partial \bar{u}_{i}}{\partial x_{j}}$

$d$ is the distance to the nearest wall, $\kappa=0.41$ is the von Karman constant, and $C_{\omega}=0.325$ is the WALE constant. With this spatial operator, the WALE model is designed to return the correct asymptotic $\left(\mathrm{y}^{3}\right)$ behaviour for wall-bounded flows. 
Conservation of energy gives

$\frac{\partial}{\partial t}\left(\rho e_{i}\right)+\nabla \cdot\left(\rho \vec{v} h_{i}\right)=-\nabla \cdot\left(k_{e f f} \nabla T-\sum h_{j} \vec{j}_{j}\right)+S_{h i}$

where $e_{i}$ and $h_{i}$ are the internal energy and enthalpy of species $i . k_{\text {eff }}$ is the sum of the laminar thermal conductivity arising from the turbulence modelling. The diffusion term is defined below and $S_{h i}$ arises due to the source term arising from the particle coupling.

The conservation equation for the mass of species $i$ gives:

$\frac{\partial}{\partial t}\left(\rho Y_{i}\right)+\nabla \cdot\left(\rho \vec{v} Y_{i}\right)=-\nabla \cdot \vec{J}_{i}+S_{Y_{i}}$

where $S_{Y_{i}}$ is the rate of production by evaporation from the dispersed phase. Mass diffusion of water vapour between the air from the nasal cavity with the external surrounding air occurs through Fick's Law:

$j_{i}=-\left(\rho D_{i . m}+\frac{\mu_{t}}{S c_{t}}\right) \nabla Y_{i}-D_{T, i} \frac{\nabla T}{T}$

where $S c_{t}$ is the effective Schmidt number for the turbulent flow:

$S c_{t}=\frac{\mu_{t}}{\rho D_{t}}$

and $D_{T, i}$ is the Soret coefficient.

\subsection{Aerosol Modelling}

The equation of motion for the particles (droplets) is given by:

$m_{p} \frac{d \vec{u} p}{d t}=\vec{F}_{d}+m_{p} \vec{g}$

where the subscripts $p$ and $g$ represent particle and gas (air) phases, $m_{p}$ is the particle mass, $\vec{g}$ is the acceleration due to gravity and $F_{d m}$ is the drag force per unit mass given by:

$F_{d m}=\frac{18 \mu}{\rho_{p} d_{p}^{2}} \frac{C_{d} R e}{24}\left(u_{g}-u_{p}\right)=\frac{\left(u_{g}-u_{p}\right)}{\tau}$

where $\tau$ is the particle relaxation time.

A dynamic drag coefficient was used to account for variations in the droplet shape when an initially spherical droplet moves through a gas. The slip velocity between the droplet and gas contributes to the droplet distortion and is significant when the Weber number is large. In this case, the peak droplet Weber number was estimated (at peak sneeze velocity) to be in the order of 0.3 to 3 based on $W e=\rho_{g} v^{2} d_{p} / \sigma$ where the peak velocity was estimated as $30 \mathrm{~m} \mathrm{~s}^{-1}, \sigma=0.07194$ $\mathrm{N} \mathrm{m}^{-1}$, and the range of diameters was 20 to $200 \mu \mathrm{m}$. This suggests relatively weak distortion and breakup, but it could be more significant in larger droplets. The dynamic drag coefficient accounts for the effects of droplet distortion, linearly varying the drag between that of a sphere to a value of 1.54 corresponding to a disk (Liu et al., 1993). This is defined as:

$C_{d}=C_{d, \text { sphere }}(1+2.632 y)$ 
where

$$
C_{d, \text { sphere }}=\left\{\begin{array}{cc}
0.424 & R e>1000 \\
\frac{24}{\operatorname{Re}\left(1+\frac{1}{6} R^{\frac{2}{3}}\right)} & \operatorname{Re}<1000
\end{array}\right.
$$

$y$ is the droplet distortion, given by the second-order ordinary differential equation:

$$
\frac{d^{2} y}{d t^{2}}=-\frac{C_{d} \mu_{l}}{\rho_{l} r^{2}} \frac{d y}{d t}-\frac{C_{k} \sigma}{\rho_{l} r^{3}} y+\frac{C_{F}}{C_{b}} \frac{\rho_{g}}{\rho_{l}} \frac{u^{2}}{r^{2}}
$$

The constant terms have values of $C_{F}=1 / 3 ; C_{k}=8 ; C_{D}=5 ; C_{b}=1 / 2$ from O'Rourke and Taylor (1987)'s Taylor Analogy Breakup model. Droplet breakup that occurs for We $>1$ is modelled with the Schmehl model (Schmehl et al., 1998) breakup, which can distinguish between three breakup regimes, Bag Breakup Multimode Breakup, and Shear Breakup, based on the droplet Weber and Ohnesorge number. For water droplets, the Ohnesorge number is oh $\mu_{l} / \sqrt{\rho_{l} D \sigma_{l}} \quad($ Oh $<0.1)$.

Multicomponent particles were selected to model the sneeze droplets. The particle mass $m$ is the sum of the masses of the components:

$\mathrm{m}=\sum_{i} m_{i}$

The component mass fraction in this study was set to 0.9524 for liquid water and 0.0476 for the non-volatile viral species. A heat balance equation governs the droplet temperature

$m_{p} c_{p} \frac{d T_{p}}{d t}=h A_{p}\left(T_{g}-T_{p}\right)-L \frac{d m}{d t}$

which calculated the droplet temperature from a heat balance involving convection and evaporation.

The onset of droplet vaporisation occurs when the temperature of the droplet reaches the vaporisation temperature $T_{\text {vap }}$ and continues until the droplet's volatile fraction is completely consumed. In Ansys Fluent, the onset of the vaporisation law is determined by setting the value of $T_{\text {vap }}$ Which is a modelling parameter that has no physical significance. To ensure the droplet evaporation rates are consistent with reported values, the $T_{\text {vap }}$ alue was evaluated against Redrow et al. (2011), shown in Fig. 2(a). As the ambient relative humidity increased, the $T_{\text {vap }}$ setting value increased to match the results of Redrow et al. (2011). Fig. 2(a) compares the evaporation of pure water droplets with different sizes obtained from the current study and Redrow et al. (2011). The presence of a non-volatile or soluble component affects the water vapour pressure over the droplet surface and affects the evaporation rate. Therefore, the final size distribution of multi-component droplets will differ from pure water droplets (e.g., $50 \%$ of the original size for a solute content of $88 \mathrm{~g} \mathrm{~L}^{-1}$ (Nicas et al., 2005; Anand and Phuleria, 2021)). Fig. 2(b) shows the droplet temperature reach a steady value equal to $T_{\text {vap }}$.

\subsection{Boundary Condition}

The nasal cavity mucosal wall temperature was set to $34^{\circ} \mathrm{C}$ at a fully saturated state, while the nasal vestibule lined with nasal hair has a zero-water vapour mass flux. The temperature setting was based on septal mucosal temperature measurements, ranging from $30.2^{\circ} \mathrm{C}$ at the end of inspiration to $34.4^{\circ} \mathrm{C}$ at the end of expiration during exhalaion (Fabricant, 1957; Lindemann et al., 2002). The exhaled airflow starts at the naso-oropharynx exit, which is assumed to have a fully conditioned state of $34^{\circ} \mathrm{C}$ and $100 \%$ saturation due to it originating from the lungs. The manikin surface temperature was set to $30^{\circ} \mathrm{C}$; clothing thermal resistance was not included, reducing the manikin temperature further. A preliminary steady-state simulation was performed to establish a natural convection thermal plume flow (Fig. 1(c)). The air density was defined with 


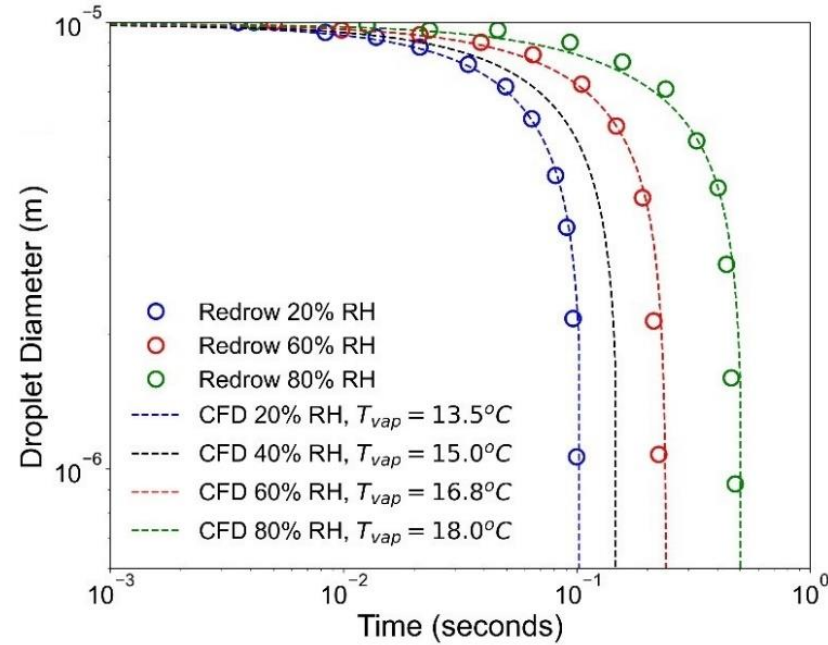

(a) Droplet evaporation profile

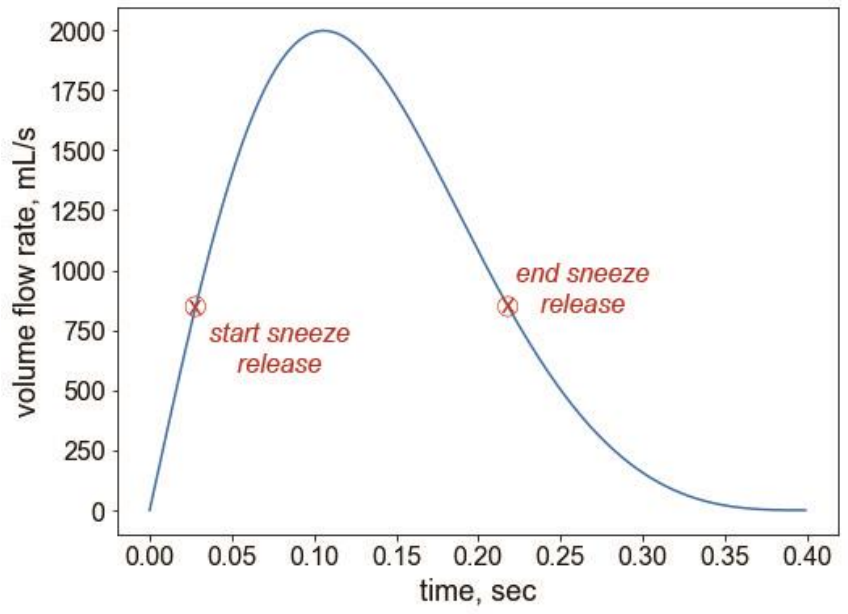

(c) Sneeze flowrate profile

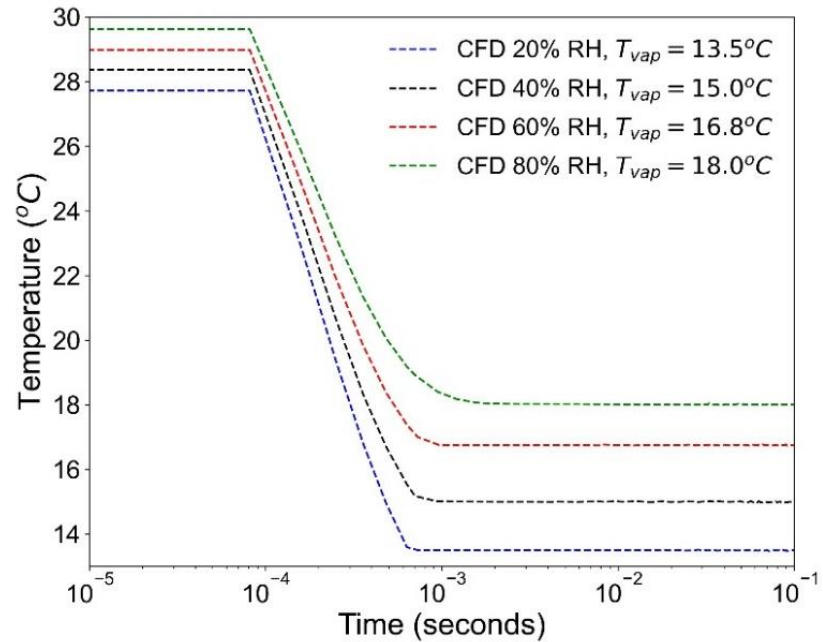

(b) Droplet temperature profile

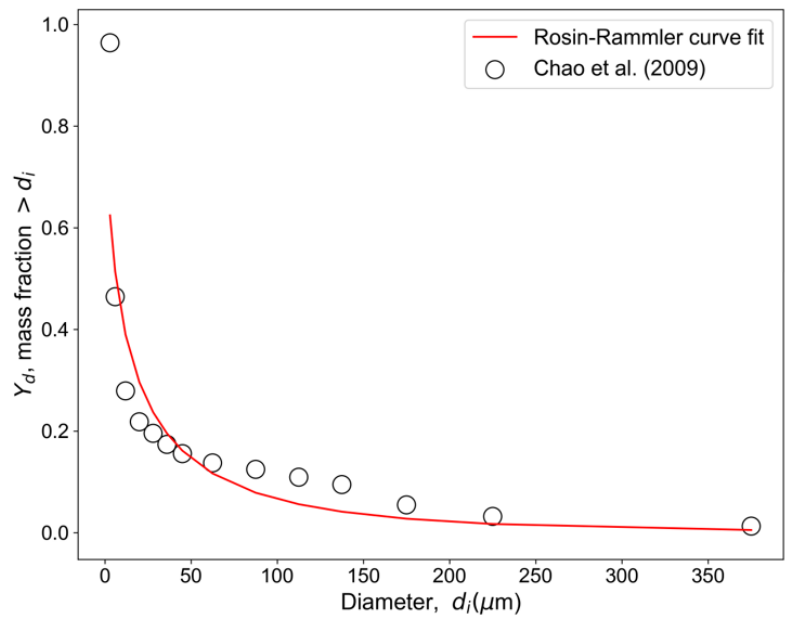

(d) Droplet size distribution

Fig. 2. (a) Droplet evaporation profile comparison with Redrow et al. (2011) at different ambient relative humidity, (b) Droplet temperature profile during evaporation at different ambient relative humidity, (c) Exhaled flowrate profile for sneezing, with labels for the start and end times of droplet injection, and (d) Sneeze droplet size distribution defined by a Rosin-Rammler distribution defined by $Y_{d}=e^{-(d / \bar{d})^{n}}$ where $\bar{d}=13.5 \mu \mathrm{m}$, and $\mathrm{n}=0.5$ to match the measured size distribution of Chao et al. (2009).

an incompressible ideal gas law (using the general equation of state) to allow a buoyant flow and thermal plume around the human body

\subsection{Breathing Profiles}

A sneeze profile from Gupta et al. (2009), which was curve fitted with sine functions, was utilised in this study and is defined as:

$$
\dot{m}=A \sin (B t+\sin (B t))
$$

where $A=0.0024465 \mathrm{~kg} \mathrm{~s}^{-1}$, and $B=7.853982 \mathrm{~s}^{-1}$. Over the period of $0.4 \mathrm{~s}$, the profile gives an equivalent exhalation tidal volume of $350 \mathrm{~mL}$. This is less than the average breathing tidal volume of 500-550 mL; however, short sneezes and coughs may not necessarily expel the full volume and is assumed to be recovered in subsequent respiration cycles. The mass flow rate breathing profiles were converted into volume flow rates $\left(\dot{v}=\frac{\dot{m}}{\rho_{\text {air }}} \times 10^{6}\right)$ shown in Fig. 2(c). The sneezed 
droplets were defined by a Rosin-Rammler function based on measured droplet number distribution of a person coughing fifty times in Chao et al. (2009) (see Fig. 2(d)). The initial size range was divided into twenty-five discrete intervals at twenty locations on a plane and was introduced at time $t=0.025 \mathrm{~s}$ and at every $\Delta t=5 \times 10^{-4} \mathrm{~s}$ until $t=0.225 \mathrm{~s}$. The droplets were released at the internal nasal valve region (approximately $1 \mathrm{~cm}$ inside the nostril).

\section{RESULTS}

\subsection{Nasal Sneezing Jets}

The airflow velocity distribution is shown in Fig. 3 in planes that pass through the (A) left nostril, (B) nose centre, and (C) the right nostril. The left and right nostril jet entrained the ambient fluid and diverged radially with axial distance. The jet proceeded until its energy was ultimately dissipated due to viscous action at the small scales, resulting in jet decay. As the mass flow rate

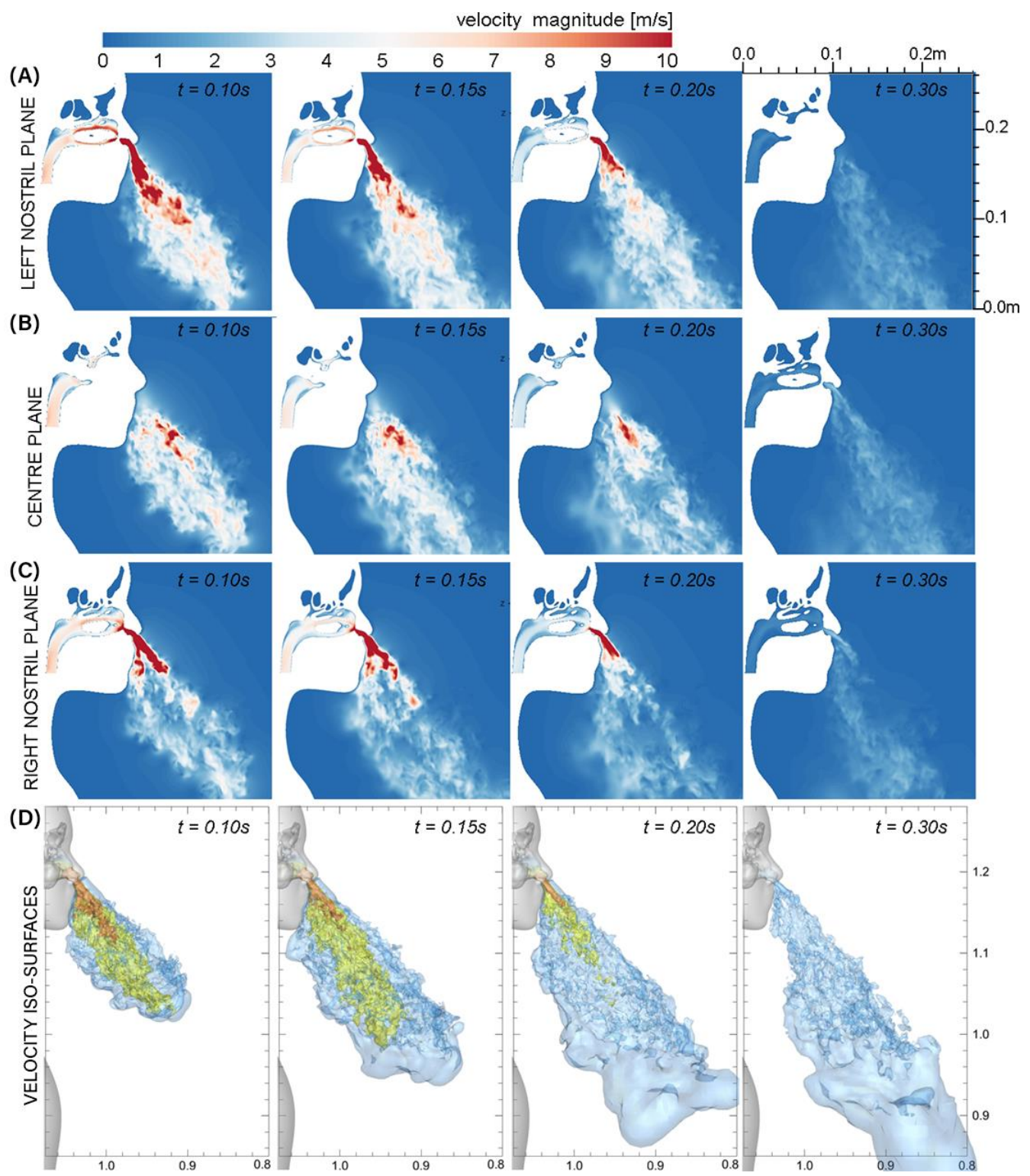

Fig. 3. Velocity magnitude contours on planes that pass through the (A) left nostril, (B) nose centre, and (C) right nostril. (D) Velocity iso-surfaces of $1 \mathrm{~m} \mathrm{~s}^{-1}$ (blue), $5 \mathrm{~m} \mathrm{~s}^{-1}$ (yellow), and $10 \mathrm{~m} \mathrm{~s}^{-1}$ (orange) are overlayed on each other to depict the sneeze plume. Four snapshots during the sneeze are shown to demonstrate the sneeze plume evolution. 
decreased over time, the high-velocity region near the nostril, known as the jet potential core,diminished. The nasal sneeze jets pass over the curved upper lip surface, and boundary layer separation occurs, which can be seen in the right nostril plane (Fig. 3(C)). The centre plane in Fig. 3(B) demonstrates the velocity distribution in a region where left and right nostril sneeze jets merged. Velocity iso-surfaces show high velocities $\left(\geq 10 \mathrm{~m} \mathrm{~s}^{-1}\right)$ are present up to $t=0.2 \mathrm{~s}$, however the residue momentum transports the sneeze jet into a slow moving puff $\left(1 \mathrm{~m} \mathrm{~s}^{-1}\right.$ in Fig. 3(D)). An animation of the sneeze jets over time is given in the Supplementary Material.

Fig. 4 shows instantaneous velocity profiles along six lines for both right and left planes at
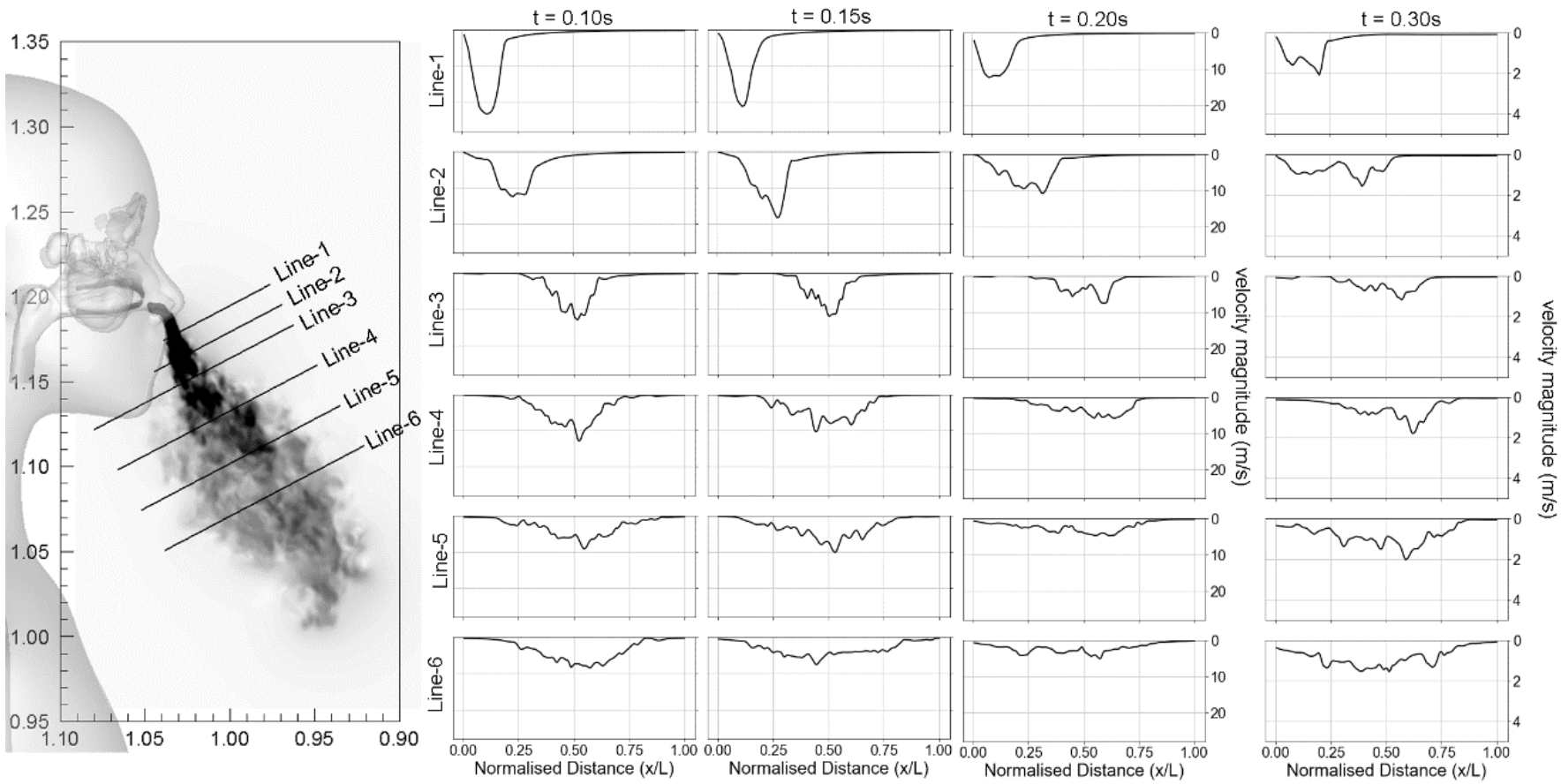

(a) Left nostril plane
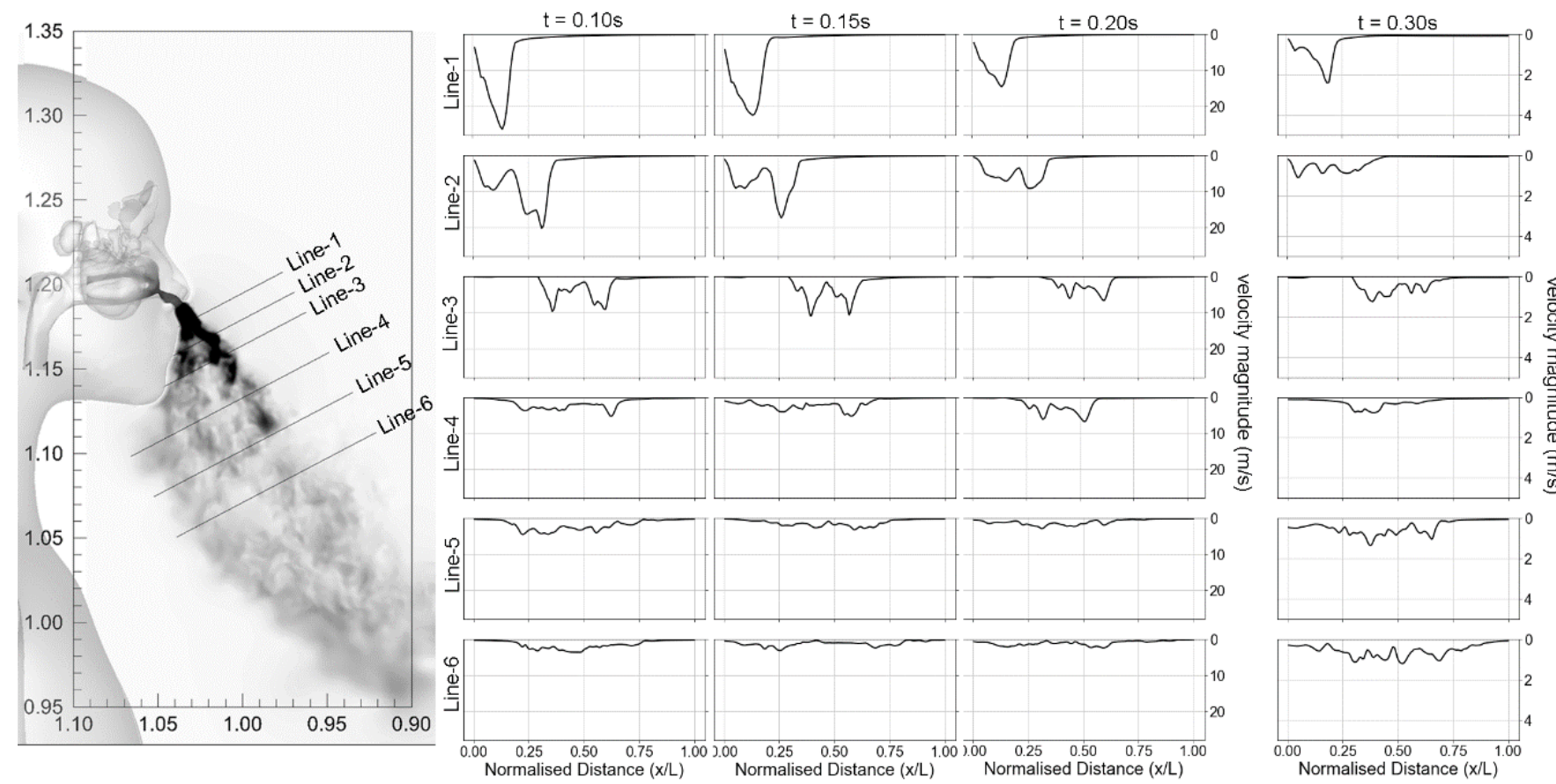

(b) Right nostril plane

Fig. 4. Velocity profile along monitoring lines on the (a) left and (b) right nostril planes. 
different times. At $t=0.1 \mathrm{~s}$ peak velocities reached $23.4 \mathrm{~m} \mathrm{~s}^{-1}$ in the left plane and $28.3 \mathrm{~m} \mathrm{~s}^{-1}$ in the right plane, and these peaks diminished over time as the sneeze airflow reduced. There were multiple peaks in the right plane along line 2 and 3 . The velocity profiles spread radially in Lines 4-6 for both planes.

Exhaled air through the human nostrils is similar to a circular free jet, although the exhaled jet is not necessarily a circular shape but dependent on nostril geometry. Furthermore, the two nostrils produce two co-flowing parallel jets. One jet is expected to have higher velocity due to the asymmetrical nasal cavity (e.g., left/right chamber) volumes found during nasal cycling. Nevertheless, we can refer to the behaviour of a circular free jet to provide insight into the mechanisms of nasal sneezing (dual co-flowing jets).

Circular free jets are characterised both radially and axially, where the radial jet flow is divided into three broad regions, namely, (1) the centerline region, (2) the shear layer, and (3) the outer layer (Heschl et al., 2013; Miltner et al., 2015). The centreline region typically exhibits a peak flow. However, the nostril opening is not circular in a nasal sneeze, and the peak velocity is not necessarily in the centreline region. In the shear layer region, vortices are formed, leading to energy transfer between turbulence structures of larger scales to smaller scales. Fig. 5 demonstrates the

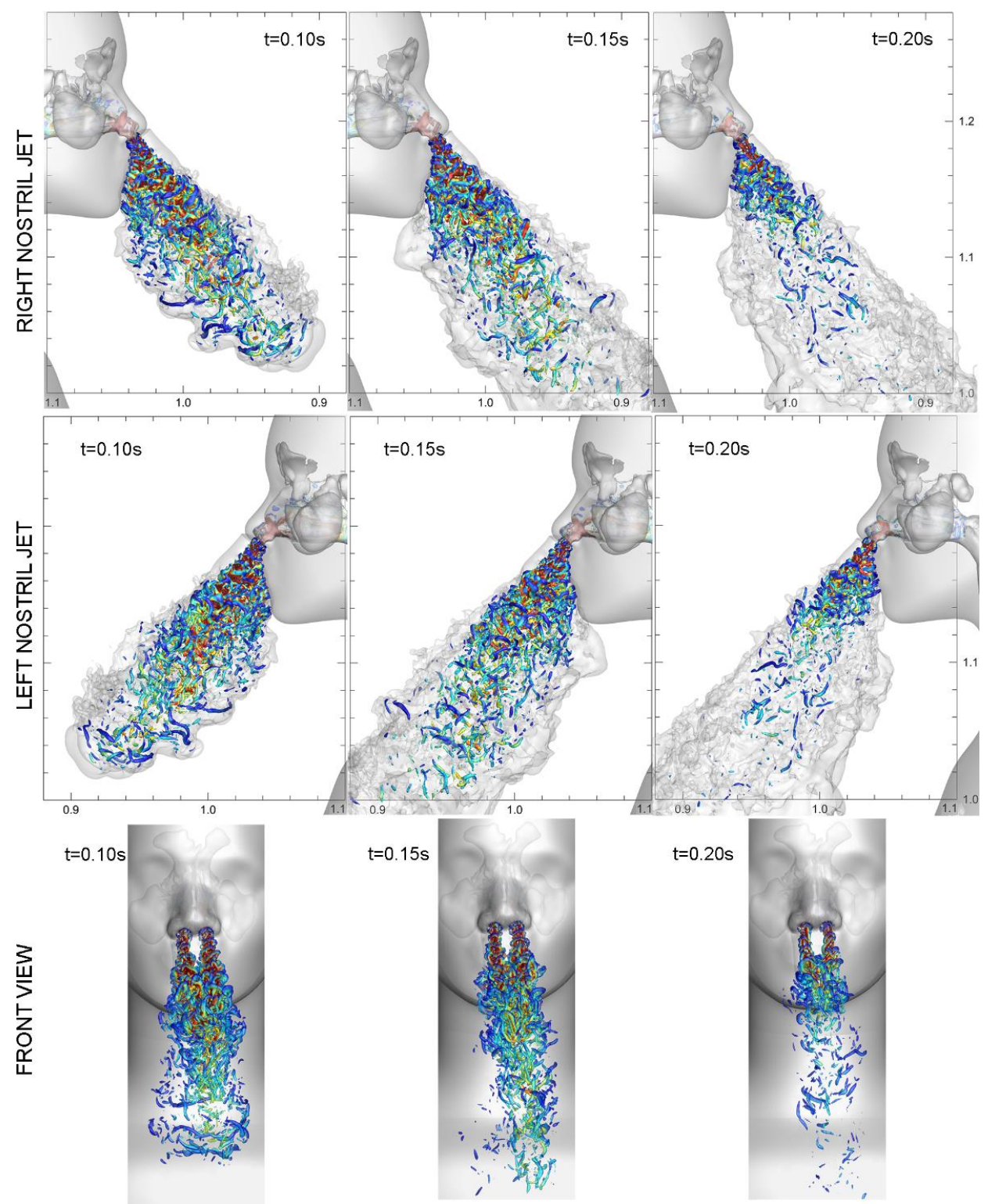

Fig. 5. Sneeze plume development at $t=0.1 \mathrm{~s}, \mathrm{t}=0.15 \mathrm{~s}$, and $\mathrm{t}=0.2 \mathrm{~s}$. The $\mathrm{Q}$-criterion is used to display the resolved turbulent vortical structures present in the flow. 
turbulence structures inside the sneeze puff visualised with a velocity iso-surface of $1 \mathrm{~m} \mathrm{~s}^{-1}$. Each jet has a strong turbulent core with ring vortices surrounding it. The attachment of the right and left nostril jets can be observed at the front view of the velocity iso-surface (Fig. 5). The region from the nostrils to the point where the inner shear layer of the jets joins is called the 'converging region'. After the converging region, the jets started interfering, and the velocity on the centre plane increased to a maximum value (see Fig. 3). The 'merging region' is identified by the converging point and the points where the two jets resemble a single jet.

\subsection{Sneeze Droplet Dispersion}

Fig. 6(a) depicts the droplet dispersion with flow streamlines at $t=0.05 \mathrm{~s}$, demonstrating an initial linear moving jet that disperses at the end of the jet. The smaller droplets (blue colours) at the jet plume's edges display rollup effects caused by the flow streamlines. The flow streamlines show an air entrainment effect where recirculating flow occurs at the shear layer. The droplets were overlayed with the sneeze plume iso-surface of $1 \mathrm{~m} \mathrm{~s}^{-1}$ in Fig. $6(\mathrm{~b})$ which shows some droplets move out of the plume suggesting gravitational sedimentation effects are prominent.

Fig. 7 shows the droplet dispersion from nostril sneezing coloured by diameter and velocity at different sneeze times. The larger sneeze droplets (red colour) travel further under its own inertia and gravitational sedimentation effects. The smaller sneeze droplets (blue colour) remain in the plume's core. At $t=0.2 \mathrm{~s}$, the sneeze plume exhibited a dominant vortex ring which quickly disintegrated into smaller vortex rings. The vortex ring entrains the smaller particles, and at $t=0.4 \mathrm{~s}$,

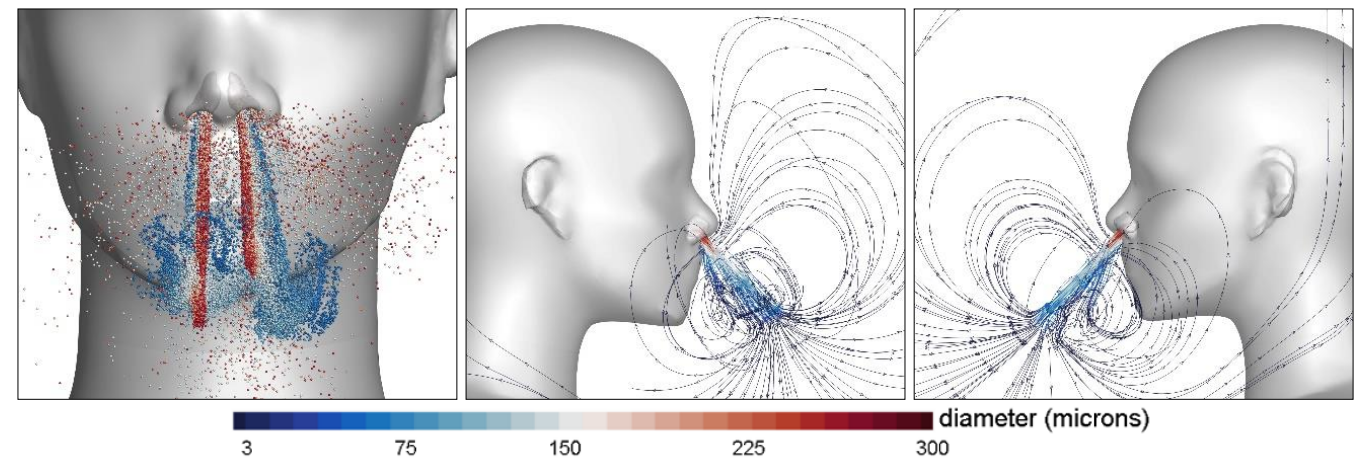

(a) Droplet dispersion with flow streamlines at $\mathrm{t}=0.05 \mathrm{~s}$

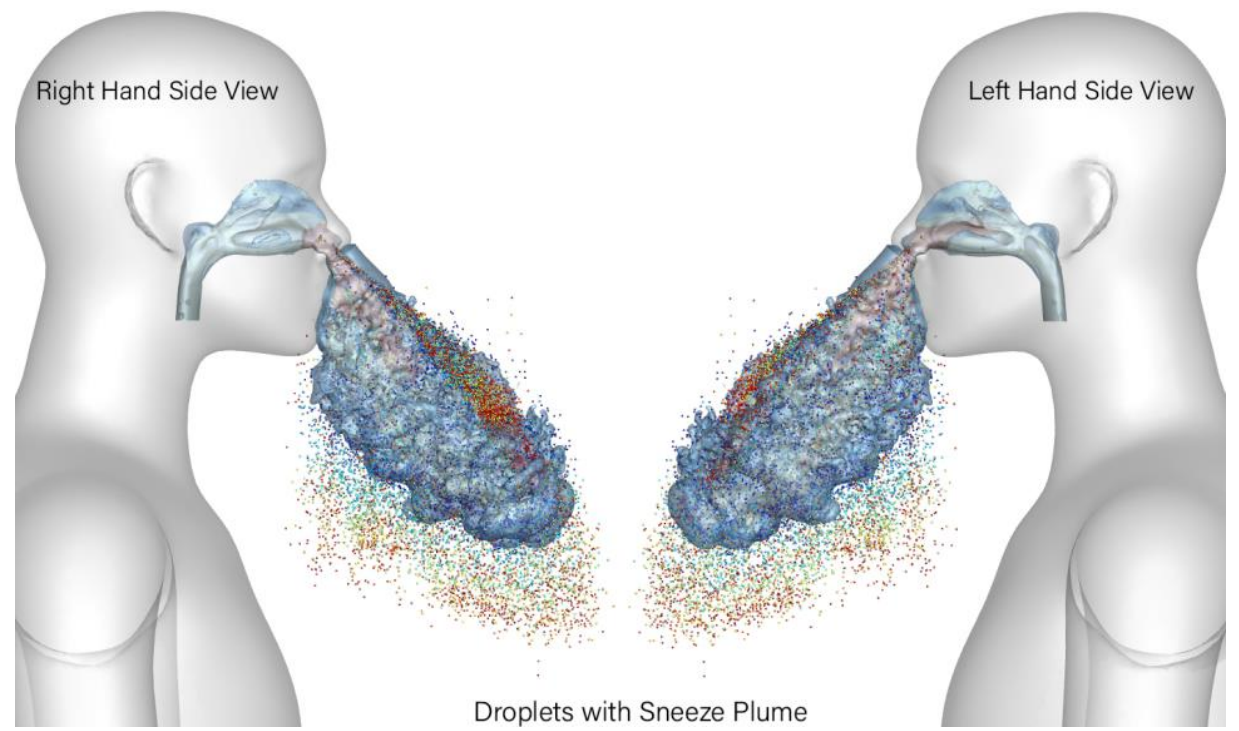

(b) Droplet dispersion with sneeze plume at $\mathrm{t}=0.10 \mathrm{~s}$, where the velocity iso-surface of $1 \mathrm{~m} \mathrm{~s}^{-1}$ is depicted

Fig. 6. Combined depiction of droplet dispersion (a) overlayed with flow streamlines at $t=0.05 \mathrm{~s}$, and (b) overlayed with a sneeze plume. 


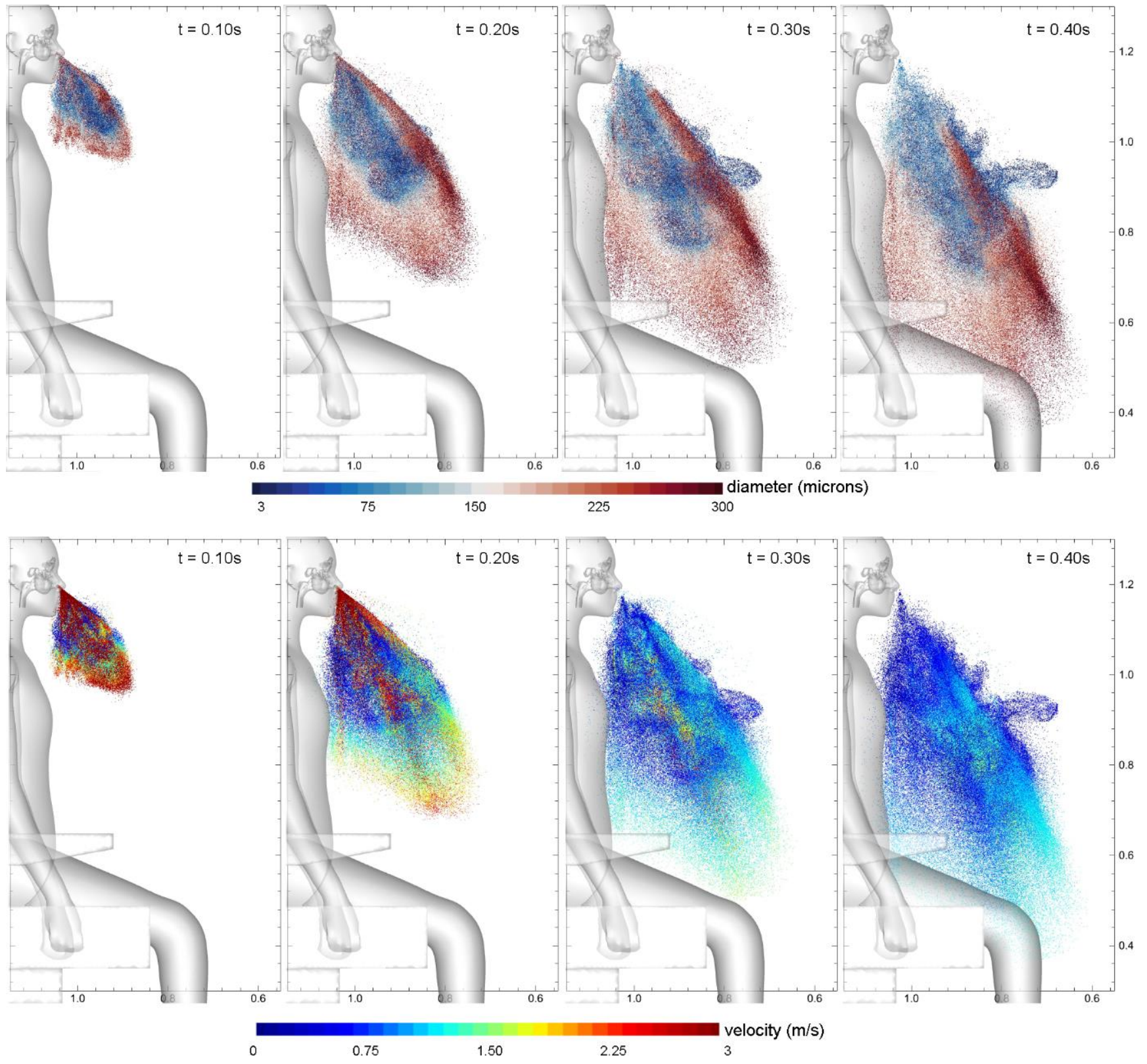

Fig. 7. Droplet size and velocity dispersion from a sneeze shown at different times of the sneeze.

these small rings exit the sneeze plume radially. At the end of the sneeze, the airflow is reduced, and the initial jet momentum dissipates. The larger droplets begin to settle under the influence of gravity. In contrast, the smaller droplets remain suspended in the air.

Fig. 8 shows the flow field state (temperature and velocity contours) at the end of the sneeze at time $t=0.4 \mathrm{~s}$ allowing a preview of the likelihood of viral exposure in close contact from the sneeze. The temperature contours show a persistent thermal plume accelerating upward from the head, while the sneeze temperature decreases towards the ambient air temperature. The velocity magnitude shows a peak velocity of $1.2 \mathrm{~m} \mathrm{~s}^{-1}$ at the most distal location from the nostril as the two nostril jets moved downwards.

The velocity components (Figs. 8(c), 8(d), and 8(e)) show a strong oscillatory motion in the $x$-direction (lateral, left to right direction), suggesting continuous mixing between the two jets. The $y$-veloctiy components show two distinct regions: A rising thermal plume above the head and a strong descending flow from the nostrils. The $z$-velocity (forward-back direction) contour shows a dominant forward motion, contributing to some droplets moving away from the jet as a sneeze puff. The highly mixed positive and negative z-velocity component suggests further oscillatory motion. 


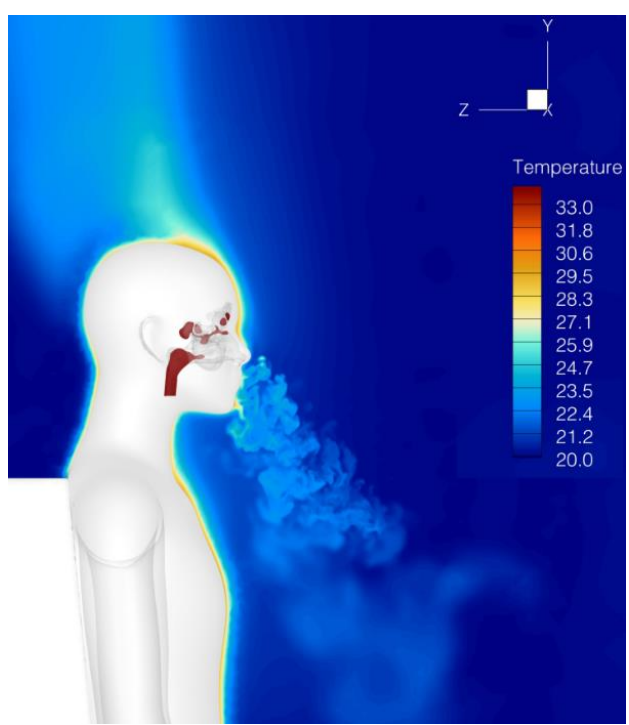

(a) Temperature contour

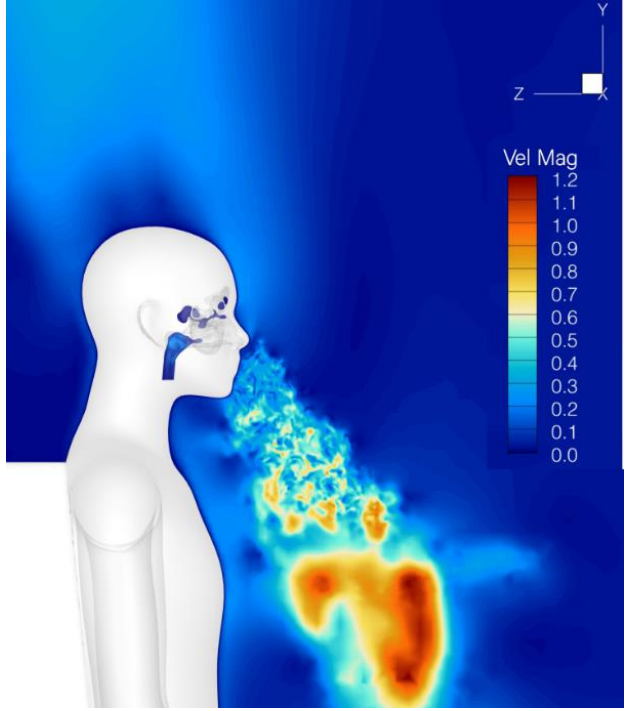

(b) Velocity magnitude contour

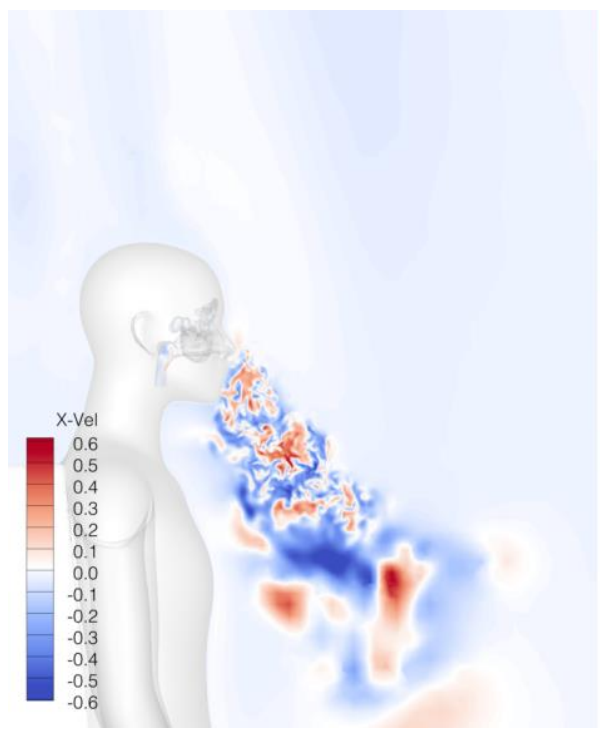

(c) $x$-velocity (lateral)

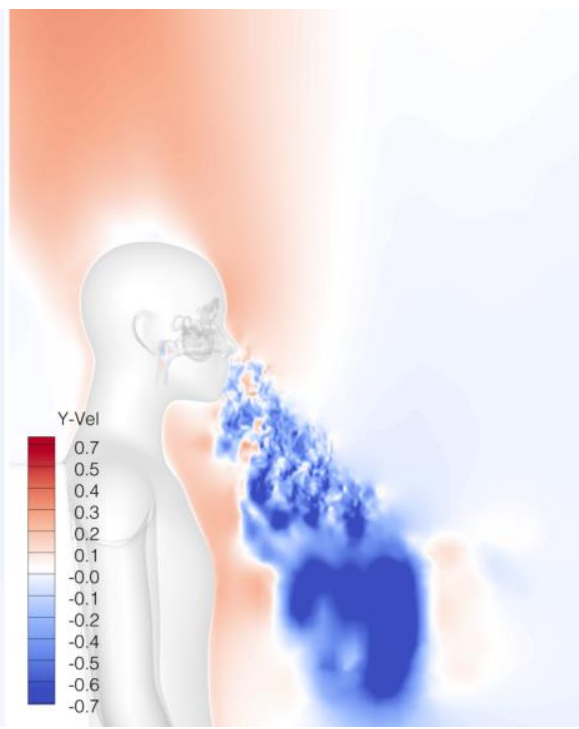

(d) $y$-velocity (vertical)

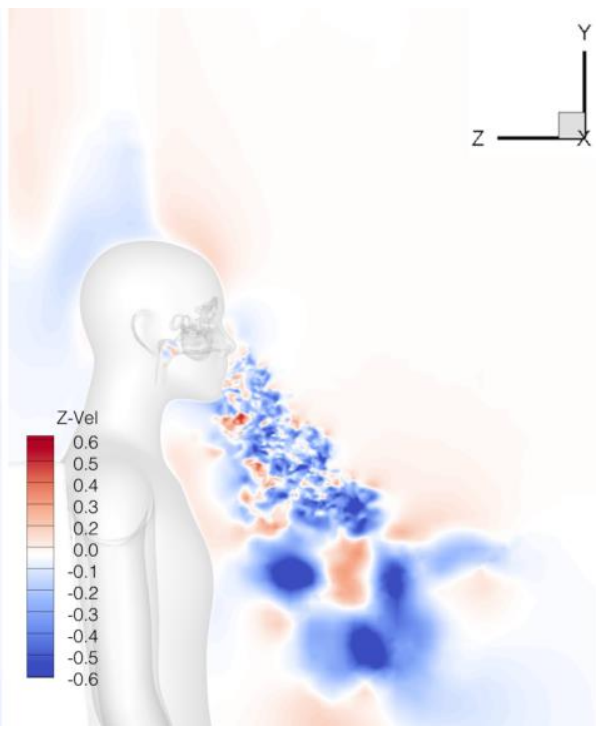

(e) z-velocity (forward-back)

Fig. 8. (a)Temperature and (b) velocity magnitude contours in the nose centre plane at the end of the sneeze $t=0.4 \mathrm{~s}$. Velocity component contours taken in the nose centre plane for (c) $x$-velocity, (d) $y$-velocity, and (e) z-velocity components.

\section{DISCUSSION}

According to World Health Organization (WHO), the SARS-CoV-2 virus can spread from an infected person by aerosols during coughing, sneezing, or breathing. While many studies investigated the dispersion of SARS-CoV-2 aerosols from the mouth due to coughing, aerosols from nasal sneezing have remained uninvestigated. Therefore, this study examined the exhaled jets and viral-laden aerosol dispersion during nasal sneezing. During nasal sneezing, the nostrils resemble converging circular nozzles that accelerate fluid. The airflow jets discharged from the nostrils expanded radially while moving axially. The mixing of these jets was similar to a co-flow parallel jet. During exhalation (breathing or sneezing), the air coming from the lung is partitioned between the nasal passages based on the cross-sectional area of each passage (Zhao et al., 2004).

For nasal geometries with non-symmetrical nasal passages and nares, the interaction of the two parallel jets will alter, and the attachment of right and left jets occur at a shorter axial distance. In this study, the nasal passages and nostril dimensions were similar, but one side was more patent resulting in a faster jet in one nostril. The exhaled airflow jets produce maximum air velocities found in the 
jet plume's core. This has been previously stated by Salati et al. (2021). The aerosols follow the direction of the exhaled flow while the jets have the initial momentum, and at the end of the sneeze, the dispersion will be dominated by gravity, which is shown by the y-velocity contours in Fig. 8 .

There appears to be a 'sneeze puff' similar to the cough puff that has been found from oral coughing (Fabregat et al., 2021), evident by the droplets moving forwards away from the main jet flow (Fig. 6) and the z-velocity contours (Fig. 8(e)). According to the current literature (Leder and Newman, 2005; Bourouiba, 2020), aerosols exiting from the mouth can travel meters from the subject. The single circular jet exhaled from the mouth moves horizontally and carries the viruses considerably until the jet loses its momentum. However, the viral aerosols exiting the nostrils from nasal sneezing is orientated towards the ground, limiting the virus's travel distance. The results showed that the smaller viral droplets remained suspended in the air at the end of nasal sneezing. These droplets can be carried away by the indoor or outdoor air currents, which necessitates wearing a mask despite the social distancing.

The flow field state at the end of the sneeze $(t=0.4 \mathrm{~s})$ shows a moving sneeze downwards and a horizontal vortex puff that is likely to continue dispersing the viruses throughout a room. Furthermore, the persistent thermal plume from the body will transport droplets upwards and can be assisted by a displacement type ventilation that moves air from the ground upwards. In this study, ambient air is at rest and room ventilation was not considered in the simulations. Air currents from room ventilation or thermal buoyancy can affect the exhaled airflow characteristics and aerosol dispersion. Nasal sneezing follows a breathing cycle which usually takes about 4 seconds. Further extensions of the current work can include a longer simulation time to understand the effect of respiration on exhaled flow and aerosol transport after nasal sneezing and evaluate the effectiveness of different ventilation systems to remove the viral droplets.

\section{CONCLUSION}

To complement the existing studies of cough jets from COVID-19 infected subjected, this study investigated viral-laden aerosols exiting the nostrils due to nasal sneezing. A seated manikin with a human nasal cavity was modelled to investigate the viral-laden aerosol dispersion and exhaled airflow jet characteristics from the nostril during nasal sneezing. A computational study of a human nasal sneeze was performed with using a RANS/LES turbulence model to provide realistic transient flow fields. From the results, the following conclusions were made:

- $\quad$ Exhaled airflows during nasal sneezing are similar to turbulent free jets in parallel.

- The right and left jets interfere with each other and merge after a specified axial distance.

- The jets lose their initial momentum as the sneeze mass flow rate decreases, and the jets diverge radially with axial distance.

- The sneeze aerosol plume can be categorized as V-shaped exiting the two nostrils. The particles larger than 150 microns sediment rapidly to the bottom of the plume due to the gravitational forces, while the smaller particles, less than 10 microns become suspended in the air within the fringes of the sneeze plume.

- A 'sneeze puff that transports the aerosols away from the body was identified, similar to the buoyant puff observed from oral coughs.

\section{SUPPLEMENTARY MATERIAL}

Supplementary material for this article can be found in the online version at https://doi. org/10.4209/aaqr.210338

\section{REFERENCE}

Alonso, C., Raynor, P.C., Davies, P.R., Torremorell, M. (2015). Concentration, size distribution, and infectivity of airborne particles carrying swine viruses. PLoS One 10, e0135675. https://doi.org/ 10.1371/journal.pone.0135675

Anand, A., Phuleria, H.C. (2021). Assessment of indoor air quality and housing, household and 
health characteristics in densely populated urban slums. Environ. Dev. Sustainability https://doi.org/10.1007/s10668-021-01923-x

Anand, S., Mayya, Y. (2020). Size distribution of virus laden droplets from expiratory ejecta of infected subjects. Sci. Rep. 10, 21174. https://doi.org/10.1038/s41598-020-78110-x

Arumuru, V., Pasa, J., Samantaray, S.S. (2020). Experimental visualization of sneezing and efficacy of face masks and shields. Phys. Fluids 32, 115129. https://doi.org/10.1063/5.0030101

Bahl, P., de Silva, C., Bhattacharjee, S., Stone, H., Doolan, C., Chughtai, A.A., Maclntyre, C.R. (2021). Droplets and aerosols generated by singing and the risk of coronavirus disease 2019 for choirs. Clin. Infect. Dis. 72, e639-e641. https://doi.org/10.1093/cid/ciaa1241

Bathula, S., Anand, S., Thajudeen, T., Mayya, Y.S., Chaudhury, P., Shashank, C. (2021). Survival of expiratory aerosols in a room: Study using a bi-compartment and bi-component indoor air model. Aerosol Air Qual. Res. 21, 200547. https://doi.org/10.4209/aaqr.200547

Behera, S., Bhardwaj, R., Agrawal, A. (2021). Effect of co-flow on fluid dynamics of a cough jet with implications in spread of COVID-19. Phys. Fluids 33, 101701. https://doi.org/10.1063/ 5.0064104

Bourouiba, L. (2020). Turbulent gas clouds and respiratory pathogen emissions: Potential implications for reducing transmission of COVID-19. JAMA 323, 1837-1838. https://doi.org/ 10.1001/jama.2020.4756

Cao, G., Liu, S., Boor, B.E., Novoselac, A. (2015). Characterizing the dynamic interactions and exposure implications of a particle-laden cough jet with different room airflow regimes produced by low and high momentum jets. Aerosol Air Qual. Res. 15, 1955-1966. https://doi.org/10.4209/aaqr.2015.03.0146

Chao, C.Y.H., Wan, M.P., Morawska, L., Johnson, G.R., Ristovski, Z., Hargreaves, M., Mengersen, K., Corbett, S., Li, Y., Xie, X. (2009). Characterization of expiration air jets and droplet size distributions immediately at the mouth opening. J. Aerosol Sci. 40, 122-133. https://doi.org/ 10.1016/j.jaerosci.2008.10.003

Crawford, C., Vanoli, E., Decorde, B., Lancelot, M., Duprat, C., Josserand, C., Jilesen, J., Bouadma, L., Timsit, J.F. (2021). Modeling of aerosol transmission of airborne pathogens in ICU rooms of COVID-19 patients with acute respiratory failure. Sci. Rep. 11, 11778. https://doi.org/ 10.1038/s41598-021-91265-5

Dbouk, T., Drikakis, D. (2020). On coughing and airborne droplet transmission to humans. Phys. Fluids 32, 053310. https://doi.org/10.1063/5.0011960

Diwan, S.S., Ravichandran, S., Govindarajan, R., Narasimha, R. (2020). Understanding transmission dynamics of COVID-19-type infections by direct numerical simulations of cough/sneeze flows. Trans. Indian Natl. Acad. Eng. 5, 255-261. https://doi.org/10.1007/s41403-020-00106-w

Duguid, J. (1946). The size and the duration of air-carriage of respiratory droplets and dropletnuclei. Epidemiol. Infect. 44, 471-479. https://doi.org/10.1017/s0022172400019288

El Hassan, M., Assoum, H., Bukharin, N., Al Otaibi, H., Mofijur, M., Sakout, A. (2022). A review on the transmission of COVID-19 based on cough/sneeze/breath flows. Eur. Phys. J. Plus 137, 1. https://doi.org/10.1140/epjp/s13360-021-02162-9

Fabregat, A., Gisbert, F., Vernet, A., Dutta, S., Mittal, K., Pallarès, J. (2021). Direct numerical simulation of the turbulent flow generated during a violent expiratory event. Phys. Fluids 33, 035122. https://doi.org/10.1063/5.0042086

Fabricant, N.D. (1957). The topical temperature of clinically normal nasal and pharyngeal mucous membranes. AMA Arch Otolaryngol. 66, 275-277. https://doi.org/10.1001/archotol.1957. 03830270033006

Feng, Y., Marchal, T., Sperry, T., Yi, H. (2020). Influence of wind and relative humidity on the social distancing effectiveness to prevent COVID-19 airborne transmission: A numerical study. J. Aerosol Sci. 147, 105585. https://doi.org/10.1016/j.jaerosci.2020.105585

Feng, Y., Zhao, J., Spinolo, M., Lane, K., Leung, D., Marshall, D., Mlinaric, P. (2021). Assessing the filtration effectiveness of a portable ultraviolet air cleaner on airborne SARS-CoV-2 laden droplets in a patient room: A numerical study. Aerosol Air Qual. Res. 21, 200608. https://doi.org/10.4209/aaqr.200608

Fontes, D., Reyes, J., Ahmed, K., Kinzel, M. (2020). A study of fluid dynamics and human physiology factors driving droplet dispersion from a human sneeze. Phys. Fluids 32, 111904. https://doi.org/10.1063/5.0032006 
Ge, H., Chen, L., Xu, C., Cui, X. (2021). Large-eddy simulation of droplet-laden cough jets with a realistic manikin model. Indoor Built Environ. https://doi.org/10.1177/1420326X211032247

Gorbunov, B. (2021). Aerosol particles generated by coughing and sneezing of a SARS-CoV-2 (COVID-19) host travel over 30 m distance. Aerosol Air Qual. Res. 21, 200468. https://doi.org/ 10.4209/aaqr.200468

Gupta, J., Lin, C.H., Chen, Q. (2009). Flow dynamics and characterization of a cough. Indoor Air 19, 517-525. https://doi.org/10.1111/j.1600-0668.2009.00619.x

Gupta, J.K., Lin, C.H., Chen, Q. (2010). Characterizing exhaled airflow from breathing and talking. Indoor Air 20, 31-39. https://doi.org/10.1111/j.1600-0668.2009.00623.x

Heschl, C., Inthavong, K., Sanz, W., Tu, J. (2013). Evaluation and improvements of RANS turbulence models for linear diffuser flows. Comput. Fluids 71, 272-282. https://doi.org/ 10.1016/j.compfluid.2012.10.015

Heschl, C., Inthavong, K., Sanz, W., Tu, J. (2014). Nonlinear eddy viscosity modeling and experimental study of jet spreading rates. Indoor Air 24, 93-102. https://doi.org/10.1111/ina.12050

Hinze, J. (1975). Turbulence. McGraw-Hill Classic Textbook Reissue Series.

Hui, D.S., Chow, B.K., Chu, L., Ng, S.S., Lee, N., Gin, T., Chan, M.T.V. (2012). Exhaled air dispersion during coughing with and without wearing a surgical or N95 mask. PLoS One 7, e50845. https://doi.org/10.1371/journal.pone.0050845

Inthavong, K., Ge, Q.J., Li, X., Tu, J.Y. (2013). Source and trajectories of inhaled particles from a surrounding environment and its deposition in the respiratory airway. Inhalation Toxicol. 25, 280-291. https://doi.org/10.3109/08958378.2013.781250

Inthavong, K., Shang, Y., Wong, E., Singh, N. (2020). Characterization of nasal irrigation flow from a squeeze bottle using computational fluid dynamics. Int. Forum Allergy Rhinol. 10, $29-40$. https://doi.org/10.1002/alr.22476

Ji, Y., Qian, H., Ye, J., Zheng, X. (2018). The impact of ambient humidity on the evaporation and dispersion of exhaled breathing droplets: A numerical investigation. J. Aerosol Sci. 115, 164172. https://doi.org/10.1016/j.jaerosci.2017.10.009

Johnson, G., Morawska, L., Ristovski, Z., Hargreaves, M., Mengersen, K., Chao, C.Y.H., Wan, M., Li, Y., Xie, X., Katoshevski, D. (2011). Modality of human expired aerosol size distributions. J. Aerosol Sci. 42, 839-851. https://doi.org/10.1016/j.jaerosci.2011.07.009

Katre, P., Banerjee, S., Balusamy, S., Sahu, K.C. (2021). Fluid dynamics of respiratory droplets in the context of COVID-19: Airborne and surfaceborne transmissions. Phys. Fluids 33, 081302. https://doi.org/10.1063/5.0063475

Khosronejad, A., Santoni, C., Flora, K., Zhang, Z., Kang, S., Payabvash, S., Sotiropoulos, F. (2020). Fluid dynamics simulations show that facial masks can suppress the spread of COVID-19 in indoor environments. AIP Adv. 10, 125109. https://doi.org/10.1063/5.0035414

Leder, K., Newman, D. (2005). Respiratory infections during air travel. Internal Med. J. 35, 50-55. https://doi.org/10.1111/j.1445-5994.2004.00696.x

Lee, J., Yoo, D., Ryu, S., Ham, S., Lee, K., Yeo, M., Min, K., Yoon, C. (2019). Quantity, size distribution, and characteristics of cough-generated aerosol produced by patients with an upper respiratory tract infection. Aerosol Air Qual. Res. 19, 840-853. https://doi.org/10.4209/aaqr.2018.01.0031

Lindemann, J., Leiacker, R., Rettinger, G., Keck, T. (2002). Nasal mucosal temperature during respiration. Clin. Otolaryngol. Allied Sci. 27, 135-139. https://doi.org/10.1046/j.1365-2273. 2002.00544.x

Liu, A.B., Mather, D., Reitz, R.D. (1993). Modeling the effects of drop drag and breakup on fuel sprays. SAE Trans. 83-95. https://doi.org/10.4271/930072

Miltner, M., Jordan, C., Harasek, M. (2015). CFD simulation of straight and slightly swirling turbulent free jets using different RANS-turbulence models. Appl. Therm. Eng. 89, 1117-1126. https://doi.org/10.1016/j.applthermaleng.2015.05.048

Mittal, R., Ni, R., Seo, J.H. (2020). The flow physics of COVID-19. J. Fluid Mech. 894, F2. https://doi.org/10.1017/jfm.2020.330

Morawska, L. (2005). Indoor Air 2005: Proceedings of the $10^{\text {th }}$ International Conference on Indoor Air Quality and Climate, 2005, Tsinghua University Press, pp. 9-23.

Mygind, N., Dahl, R. (1998). Anatomy, physiology and function of the nasal cavities in health and disease. Adv. Drug Delivery Rev. 29, 3-12. https://doi.org/10.1016/S0169-409X(97)00058-6

Nicas, M., Nazaroff, W.W., Hubbard, A. (2005). Toward understanding the risk of secondary 
airborne infection: Emission of respirable pathogens. J. Occup. Environ. Hyg. 2, 143-154. https://doi.org/10.1080/15459620590918466

O'Rourke, M., Taylor, J. (1987). Referrals to a scottish drug dependence unit: A descriptive study. Br. J. Psychiatry 151, 240-243. https://doi.org/10.1192/bjp.151.2.240

Philip, K.E.J., Lewis, A., Buttery, S.C., McCabe, C., Fancourt, D., Orton, C.M., Polkey, M.I., Hopkinson, N.S. (2021). Aerosol transmission of SARS-CoV-2: Inhalation as well as exhalation matters for COVID-19. Am. J. Respir. Crit. Care Med. 203, 1041-1042. https://doi.org/10.1164/ rccm.202012-4445LE

Redrow, J., Mao, S., Celik, I., Posada, J.A., Feng, Z.G. (2011). Modeling the evaporation and dispersion of airborne sputum droplets expelled from a human cough. Build. Environ. 46, 2042-2051. https://doi.org/10.1016/j.buildenv.2011.04.011

Salati, H., Khamooshi, M., Vahaji, S., Christo, F.C., Fletcher, D.F., Inthavong, K. (2021). N95 respirator mask breathing leads to excessive carbon dioxide inhalation and reduced heat transfer in a human nasal cavity. Phys. Fluids 33, 081913. https://doi.org/10.1063/5.0061574

Scharfman, B.E., Techet, A.H., Bush, J.W.M., Bourouiba, L. (2016). Visualization of sneeze ejecta: Steps of fluid fragmentation leading to respiratory droplets. Exp. Fluids 57, 24. https://doi.org/10.1007/s00348-015-2078-4

Shah, Y., Kurelek, J.W., Peterson, S.D., Yarusevych, S. (2021). Experimental investigation of indoor aerosol dispersion and accumulation in the context of COVID-19: Effects of masks and ventilation. Phys. Fluids 33, 073315. https://doi.org/10.1063/5.0057100

Shrestha, P., DeGraw, J.W., Zhang, M., Liu, X. (2021). Multizonal modeling of SARS-CoV-2 aerosol dispersion in a virtual office building. Build. Environ. 206, 108347. https://doi.org/10.1016/ j.buildenv.2021.108347

Stadnytskyi, V., Anfinrud, P., Bax, A. (2021). Breathing, speaking, coughing or sneezing: What drives transmission of SARS-CoV-2? J. Intern. Med. 290, 1010-1027. https://doi.org/ 10.1111/joim.13335

Tao, Y., Yang, W., Inthavong, K., Tu, J. (2020). Indoor particle inhalability of a stationary and moving manikin. Build. Environ. 169, 106545. https://doi.org/10.1016/j.buildenv.2019.106545

Thatiparti, D.S., Ghia, U., Mead, K.R. (2017). Computational fluid dynamics study on the influence of an alternate ventilation configuration on the possible flow path of infectious cough aerosols in a mock airborne infection isolation room. Sci. Technol. Built Environ. 23, 355-366. https://doi.org/10.1080/23744731.2016.1222212

Van Strien, J., Shrestha, K., Gabriel, S., Lappas, P., Fletcher, D.F., Singh, N., Inthavong, K. (2021). Pressure distribution and flow dynamics in a nasal airway using a scale resolving simulation. Phys. Fluids 33, 011907. https://doi.org/10.1063/5.0036095

Wang, H., Li, Z., Zhang, X., Zhu, L., Liu, Y., Wang, S. (2020). The motion of respiratory droplets produced by coughing. Phys. Fluids 32, 125102. https://doi.org/10.1063/5.0033849

Wei, J., Tang, J.W., Borojeni, A.A., Yin, S., Martin, A., Finlay, W.H., Li, Y. (2016). Low re-inhalation of the exhaled flow during normal nasal breathing in a pediatric airway replica. Build. Environ. 97, 40-47. https://doi.org/10.1016/j.buildenv.2015.12.011

Zhang, R., Li, Y., Zhang, A.L., Wang, Y., Molina, M.J. (2020). Identifying airborne transmission as the dominant route for the spread of COVID-19. Proc. Natl. Acad. Sci. U.S.A. 117, 14857-14863. https://doi.org/10.1073/pnas.2009637117

Zhang, Y., Shang, Y., Inthavong, K., Tong, Z., Sun, B., Zhu, K., Yu, A., Zheng, G. (2019). Computational investigation of dust mite allergens in a realistic human nasal cavity. Inhalation Toxicol. 31, 224-235. https://doi.org/10.1080/08958378.2019.1647315

Zhao, K., Scherer, P.W., Hajiloo, S.A., Dalton, P. (2004). Effect of anatomy on human nasal air flow and odorant transport patterns: Implications for olfaction. Chem. Senses 29, 365-379. https://doi.org/10.1093/chemse/bjh033

Zhu, S., Kato, S., Yang, J.H. (2006). Study on transport characteristics of saliva droplets produced by coughing in a calm indoor environment. Build. Environ. 41, 1691-1702. https://doi.org/ 10.1016/j.buildenv.2005.06.024

Zuo, Z., Kuehn, T.H., Verma, H., Kumar, S., Goyal, S.M., Appert, J., Raynor, P.C., Ge, S., Pui, D.Y. (2013). Association of airborne virus infectivity and survivability with its carrier particle size. Aerosol Sci. Technol. 47, 373-382. https://doi.org/10.1080/02786826.2012.754841 